$\$$ Research Square

\title{
An Experimental Investigation on Micro Drilling of Cold Work Steel X153CrMoV12 By EDM
}

FERHAT CERITBINMEZ ( $\square$ ferhatceritbinmez@gmail.com )

Haier Group https://orcid.org/0000-0002-5615-3124

Erdoğan Kanca

Haier Group

\section{Research Article}

Keywords: Micro Drilling, EDM, MRR, EWR, SR, Hardness

Posted Date: October 21st, 2021

DOI: https://doi.org/10.21203/rs.3.rs-987596/v1

License: () (1) This work is licensed under a Creative Commons Attribution 4.0 International License. Read Full License 


\section{Abstract}

In this study, it was aimed to analyze the effects of machining parameters on the process quality by drilling holes in heat treated cold work tool steel with a hardness of 60-62 HRC using the electrical discharge machining (EDM) method and $\varnothing 2 \mathrm{~mm}$ diameter brass electrodes. In this context, drilling was performed using three different current values $(5,6,7 \mathrm{~A})$, three different voltage values $(1,2,3 \mathrm{~V})$, three different discharge pulse frequency Ton $(23,26$, $29 \mu \mathrm{s})$ as well as Toff $(3,5 \mu \mathrm{s})$ respectively, and the effects of these machining parameters on the machining time, material removal rate (MRR), electrode wear rate (EWR), surface roughness (SR) and hardness of around the white layer were analyzed using micro, macro and analytical measurements, especially with Scanning Electron Microscopy (SEM) and Energy Dispersive X-Ray Analysis (EDX). As a result of the analysis, It was observed that current, voltage, Ton and Toff had an effect on machining time, MRR, EWR, SR and hardness, but current was the most effective parameter, and also worn electrode as well as workpiece residues affected the process quality. Increasing the machining current increased sparking between the workpiece and the electrode, resulting in increased point melting and evaporation, resulting in increased average surface roughness, metal removal rate, and electrode wear rate. As a result of the high metal removal rate, the machining time was greatly reduced and the thermal effect time was reduced, which led to a decrease in the hardness variation on the machined surfaces.

\section{Introduction}

Electrical discharge machining (EDM) is an unconventional manufacturing method based on the chip removal by melting and evaporation of the workpiece as a result of rapidly repetitive electrical discharges between the electrode (cathode) and the workpiece (anode) under dielectric liquid [1-3]. The biggest advantage of this method is It can process conductive materials with high hardness without any mechanical contact with them, regardless of their hardness [4-6].

Due to these features, hard parts used in aerospace and automotive sectors as well as dies and molds materials made from these parts can be easily processed by EDM method [7-8]. The Cold work steel 1.2379 (X153CrMoV12; C: 1.50-1.60\%;Si: 0.2-0.6\%; Mn: 0.15-0.45\%; Cr: 11-12\%; Mo 0.7-0.8\%; V:0.8-1.1\%) one of the hard steels commonly used in the industry, especially in cold forming sheet-metal molds, deep drawing molds as well as in machinery and equipment such as bolt rolling rollers and combs, plastic crushing blades, cold rolling rollers [913]. It is very suitable for cutting, crushing and deep drawing applications due to its high abrasion resistance and high toughness [14]. In addition, its hardness up to $62 \pm 2 \mathrm{HRC}$ makes it attractive to use [15]. However, machining hard materials with conventional methods is not easy in terms of tool wear, energy consumption and obtaining a good surface [16-18]. Although there are studies in the literature on the high processing quality and low cost machinability of such materials, their development continues. There are valuable studies on milling and drilling of hard materials used in automotive, aircraft and aerospace, dies/molds, home appliance, medical and electronic equipment, as well as increasing the process quality of these applications [19-22]. Gao et al. examined the effect of EDM process on thermal barrier coating (TBC) layer in a two-step drilling of electron beam physical vapor deposition (EB-PVD) coated nickel-based superalloy. They investigated the effect of pulse-on time, peak current and servo speed on coating material through drilling vertical holes and inclined holes. According to their research, relatively larger pulse duration and larger peak current can cause greater thermal stress, they emphasized that it can lead to a gradient at the interface and subsequent cracking or disintegration of the coating layer. For these reasons, short pulse duration, longer pulse-off time and small peak current are recommended for EB-PVD coated EDM drilling of the EB-PVD coated nickel-based superalloy [23]. Kuppan et al. 
conducted an experimental research on the small deep hole drilling process of Inconel 718 (a high-strength, temperature-resistant nickel-based super alloy) using $\varnothing 3 \mathrm{~mm}$ diameter copper electrode in the EDM process. Response surface methodology (RSM) was used for analysis by choosing peak current, pulse on-time, duty factor and electrode speed as input parameters; material removal rate (MRR) and depth averaged surface roughness (DASR) as output parameters. As a result of the analyzes made, It was determined that MRR was mostly affected by peak current, duty factor and electrode rotation while DASR was strongly affected by peak current and pulse on-time [24]. Kumar et al. investigated the effect of machining parameters like discharge current (Ip), pulse-on time (Ton), pulse-off time (Toff), electrode material, electrode rotation, electrode size and work height on diametric overcut (DOC) and taper rate in drilling micro holes in Ti-6Al-7Nb by EDM. They reported that diametric expansion or overcut increased with the increase of Ip, Ton, Toff, electrode diameter and work height. Ip and Toff have been reported to have erratic effects on taper rate. It was reported that the increase in the current value from 4 to 7 in the use of copper electrode increased the taper ratio, while the use of brass electrodes revealed the opposite situation [25]. Dilip et al. carried out the micro-EDM drilling experiments on Inconel 718 by using the Box-Behnken experimental design. Voltage, feed rate, and electrode rotation speed were selected as input parameters on the other hand side wall roughness, MRR, overcut, and taper angle were selected as output parameters; according to the results of these experiments, it was reported that voltage is the most important factor affecting all responses in the design area [26]. Kumar et al. investigated machinability of titanium alloy (Ti-6AI-4V) by EDM. In their study, the effects of peak discharge current and pulse-on duration on material removal efficiency and rate of tool wear were analyzed by evaluating surface roughness, surface crack density, white layer thickness, material migration, phase transformation, residual stress, and microindentation hardness on machined surfaces. According to their report, they achieved the highest MMR ratio $(\sim 2.71 \mathrm{~mm} 3 / \mathrm{min})$ using the Ip $=25 \mathrm{~A}$ and Ton $=200 \mu$ s operating parameters, and the minimum surface roughness $(\mathrm{Ra} \sim 2.26 \mu \mathrm{m})$ using the Ip $=6 \mathrm{~A}$ and Ton $=50 \mu$ s parameters. As a result of the EDS analyzes on the machined surfaces, significant amounts of $\mathrm{C}, \mathrm{Cu}$ and $\mathrm{O}$ elements have been detected. This type of enriched carbon on machined surfaces deposition resulted in the formation of hard carbides, causing an increase in the microhardness value (355.66 to 418.66 HV) [27]. In this study, $2 \mathrm{~mm}$ diameter holes were drilled using the best machining parameters selected from the EDM method on the cold work tool steel, which is difficult or impossible to machine with current conventional methods due to its high hardness, and also costly. The effects of current, voltage, Ton, Toff parameters used in the experimental study on material removal rate, electrode wear rate, surface roughness and white layer hardness were successfully analyzed using Scanning Electron Microscopy (SEM) and Energy Dispersive X-Ray Analysis, and the findings are presented as a unique study. In this study, a widely used material, an increasingly important processing method and the best drilling parameters selected will be a unique support to the literature, especially for industrial applications.

\section{Materials And Methods}

\subsection{Selected test Materials}

In this study, 1.2379 (X153CrMoV12) cold work tool steel based on molybdenum and vanadium, containing high carbon and chromium, was used as workpiece. All surfaces of this steel were ground in order to be easily attached to the EDM workbench, it was cut in $75 \times 30 \times 20 \mathrm{~mm}$ dimensions so that holes could be drilled on it at equal intervals and used with a hardness of 60-62 HRC. The chemical composition, mechanical and physical properties of this steel are given in Tables 1 and 2, respectively. Since this steel has high wear resistance and high 
toughness, it is very suitable for cutting and breaking, and it was chosen as the test material because of these properties [28].

\subsection{Machining Methods}

In this study, in micro drilling 1.2379 (X153CrMoV12) hard steel material; Oscarmax SD400 ZNC PLUS 50A Industrial EDM (Electric Discharge Machine), which can give very successful results in drilling with the EDM method was used. The $\varnothing 2 \mathrm{~mm}$ diameter brass electrode (single hole tube) and Eralube Eraoil Electron (dielectric fluid) as coolant were used to obtain the micro-holes in EDM. By choosing Eralube low viscosity EDM oil: Low wear, high speed and fine surface quality were aimed. After 12 holes were drilled at a distance of $6 \mathrm{~mm}$ on the workpiece at equal intervals by EDM, the workpiece was cut into two equal parts from the middle point by WEDM (Wire Electric Discharge Machine) in order to analyze the machined surfaces of the holes as shown figure 1. For each hole drilled with different parameters, the command was given to insert the electrode to a depth of $20 \mathrm{~mm}$ in the workpiece.

\subsection{Analysis methods of machining quality}

Surface roughness, micro and macro structure, residual stress and micro hardness are measured to discuss surface integrity assessment so machined surfaces can be analyzed [29]. Surface roughness of the workpiece is an important parameter in machining technology as well as affects the mechanical performance of the workpiece and the machining cost [30]. Ra is the most used surface roughness measurement parameter is commonly used to characterize or assign a finishing grade (ISO 1302) to a machined surface or a surface about to be machined [31]. In this study, a Wave System Hommelwerke T8000 profilometer device was used for surface roughness measurements with the stylus tip set to $1 \mathrm{~mm} / \mathrm{s}$ speed and $5 \mathrm{~mm}$ scan length. The hardness change observed in the white layer due to thermal effects was measured using the Microhardness Tester FM-700e hardness tester with a Vickers pyramid indenter along the cross-section applying $100 \mathrm{~g}$ load. Thermo Fisher Scientific Apreo S Scanning Electron Microscopy (SEM) was used to provide information about the topography and composition of the sample surface in the treated regions [32]. Energy Dispersive X-Ray Analysis (EDX), referred to as EDS or EDAX, is an X-ray technique used to identify the elemental composition of materials [33]. EDS was used for the chemical detection of eroded electrode residues on the machined surfaces of the workpiece.

\subsection{Calculations of the MRR and EWR}

In the studies in the literature, it is seen that MRR and EWR are the most considered parameters in transaction performance measurements. In these measurements, the results are obtained by using variables such as weight, volume and machining time [34-36]. Formulas 1 and 2 were used to calculate Material Removal Rate (MRR) and Electrode Wear Rate (EWR), respectively. The machining time in formula 1 was determined with the help of a stopwatch in each experiment. The pre- and post-process weights of the workpiece and electrode materials in Formula 1 and 2 were weighed with the help of Kern DBS60-3 model precision balance with $0.001 \mathrm{~g}$ sensitivity. As a result of the data obtained, MRR ( $\mathrm{mg} / \mathrm{min})$ and EER (\%) values were calculated. 
$\operatorname{MRR}\left(\frac{m g}{\min }\right)=\frac{\text { Initial weigth of workpiece }- \text { final weigth of workpiece }}{\text { Machining Time }}$

$E W R(\%)=\frac{\text { Initial weigth of electrode }- \text { final weigth of electrode }}{\text { Initial weigth of electrode }} \times 100$

\section{Results And Discussions}

The special operating parameters used in this study and the process quality data obtained in line with these parameters are given in Table 3. In this table, current, voltage, Ton and Toff input parameters; machining time, MRR, EWR, SR and hardness show the output parameters. When machining a blind hole, or applying bigger diameter of electrode tube, the selected processing parameters and electrode are very important. Both GAP (gap voltage setting key) and CAP (parallel capactor selection key) values were used as 3 in accordance with the parameters given in the table and machine safe operating parameters. The lower of gap voltage, the higher of machining current, the faster of machining speed, but the more difficulty of carbon removing and accordingly this may affect the machining speed. The application of parallel capacitor may increase the machining speed, but cause electrode wear. On the other hand, if a parallel capacitor is not applied, especially when machining a extra hard material, low machining speed will occur.

It was observed that the surface roughness was high at the highest current values among the experiments shown in Table 3. With the increase of the machining current, the sparking between the workpiece and the electrode increased and the point melting and destruction increased, as a result of which the surface roughness increased. As a result of the increased metal removal rate, the machining time was significantly reduced, but the EWR increased due to the electrode doing more work as shown figure 2a. Singh et al, in their study on experimental examination and modeling of surface treatments with ANSYS in EDM method, confirmed that the parameters that affect the surface roughness the most are discharge current, tool speed, pulse-on time and duty cycle, respectively [37]. However, according to both analytical and simulation results in Ahmed et.al 's study, they reported that the effect of tool electrode rotation on debris removal is negligible [38]. The most important point to be considered here is that the viscosity of the fluid used, the pressure and the processing parameters affect the debris evacuation; as a result, the debris in the environment affects the EWR and surface roughness. In this study, increasing voltage value showed a graph similar to the results caused by current increase as shown figure $2 \mathrm{~b}$. The machining voltage has a significant influence on the tool electrode wear followed by the rotating speed of the electrode and the diameter of tool electrode was also reported by Huang et al [39]. In low arc duration, the electrode was operated more in unit time; excessive electrical density and sparking-induced abrasions occurred at the ends of the electrode, as a result of these abrasions, the abraded particles adhered to the machined surface, causing an increase in the surface roughness as shown in figure $2 \mathrm{c}$.

In Figures 3 and 4, respectively, the SEM morphology of the machined surfaces and the effects of wearing electrodes are visualized using a Thermo Fisher Scientific Apreo S brand/model scanning electron microscope.

Before each experiment, holes were drilled using a new electrode measuring $\varnothing 2 \mathrm{~mm} \times 400 \mathrm{~mm}$. At the beginning of the process, the diameter of the area where the electrode approaches the material and the hole diameter at the end of the process are not the same, this is due to the wear on the tip areas of the electrode. In Figure $4 \mathrm{~b}$ and $4 \mathrm{~d}$ show the entrance sections of the electrode as well as $4 \mathrm{a}$ and $4 \mathrm{c}$ show the hole bottom sections, respectively. As 
can be seen from Scanning Electron Microscopy (SEM) images and measurements, there was a change in size due to electrode wear. The macro images of the worn electrodes used in the experiments are shown in Fig. 5.

When the surfaces of the holes drilled into the workpiece were examined, eroded electrode residues were found on the surface. The EDAX analysis of the hole surface drilled in experiment number four is given in Fig. 6 . Energy Dispersive X-Ray Analysis (EDX), referred to as EDS or EDAX, is an x-ray technique used to identify the elemental composition of materials. According to the measurements made at three different points of the machined surface, brass elements that it does not contain in its own structure were detected on the surface of the workpiece. The chemical components of X153CrMoV12 workpiece are given in Table 1, Carbon (C), Chrome (Cr), Molybdenum (Mo), Vanadium (V) are the chemical components of this steel. Brass is the general name of yellow alloys obtained by adding zinc ( $\mathrm{Zn})$ to copper (Cu). Some other elements that can be found in brass are tin (Sn), lead $(\mathrm{Pb})$, nickel $(\mathrm{Ni})$, manganese $(\mathrm{Mn})$, iron (Fe), aluminum ( $\mathrm{Al})$, silicon ( $\mathrm{Si})$, arsenic (As), antimony (Sb) and phosphorus $(P)$. However, as seen in Fig. 6c, 6d and 6e graphs, $\mathrm{Cu}, \mathrm{Fe}, \mathrm{Mn}, \mathrm{Zn}$ elements were found on the machined surface, which is proof that the materials separated from the worn electrode were carried to the workpiece surface.

Although the hardness of the 1.2379 (X153CrMoV12) workpiece used in the experiment was approximately 720 $\mathrm{HV}_{0.10}$, the hardness value decreased to values between $580-626 \mathrm{HV}_{0.10}$ in the parts close to the drilled areas with different machining parameters due to thermal effects. As seen in Fig. 7, three different measurements were made near each hole drilled and average values were reported. The hardness values obtained from experiments 10 and 7, where the surface roughness is the highest and the lowest, respectively, and measured at $75 \mu \mathrm{m}$ intervals from the machined surface, are shown in Fig. 8.

As can be seen from the measured values, the hardness values gradually decrease as they approach the machined surfaces as shown fig. 9. This decrease is affected by the increase in the processing time. As the processing time increases, the hardness change increases as the material is more exposed to thermal effects. In the literature, it has been reported that hardness change is observed in the workpiece because thermal effects are revealed in the machining processes using the EDM method. The melting and resolidification of the material causes formation of white layer (WL) onto the top of the machined surface [40]. It was emphasized that the increase in hardness in these WL regions was more due to the iron carbon carried by the dielectric fluid [41-42]. Since the material used as the workpiece in this study is heat-treated steel, hardness changes were detected in the areas close to the processed areas with the effect of energy and heat applied during drilling with EDM. As a result of the hardness measurements, it was seen that the main hardness of the material was reached as it moved away from the machined area as shown fig. 9.

\section{Conclusion}

In this study, the following results were obtained by making Scanned electron microscopic investigation, Energy Dispersive X-Ray Analysis (EDX), roughness measurement, microhardness testing, macro and micro analyzes as a result of drilling high hardness cold work tool steel with different EDM processing parameters.

- Increasing the machining current increased sparking between the workpiece and the electrode, resulting in increased point melting and evaporation, resulting in increased average surface roughness, metal removal rate, and electrode wear rate. As a result of the high metal removal rate, the machining time was greatly 
reduced and the thermal effect time was reduced, which led to a decrease in the hardness variation on the machined surfaces.

- With the increase in the applied voltage between the electrode and the workpiece, the total energy of the spark increased. As the voltage value increased, the erosion rate increased and higher machining speed was obtained, so the EWR increased, but the surface roughness was negatively affected.

- With the increase of the erosion process time, the MRR first decreased and then increased. On the other hand, it was determined that the effect of Ton on SR, EWR and machining time was irregular due to the debris shielding from the part and the wearing electrode parts stick to the electrode surface, affecting the sparking.

- Hardness values gradually decrease in areas close to the machined surfaces. This decrease is affected by the increase in the processing time. As the processing time increases, the hardness change increases as the material is more exposed to thermal effects.

\section{Declarations}

\section{Author contribution statement}

Study conception and design: Ferhat Ceritbinmez.

Acquisition analysis and interpretation of data: Ferhat Ceritbinmez, Erdoğan Kanca

Drafting of manuscript: Ferhat Ceritbinmez.

Critical revision: Ferhat Ceritbinmez, Erdoğan Kanca

Competing interests The authors declare that they have no known competing financial interests or personal relationships that could have appeared to influence the work reported in this paper.

Funding This research did not receive any specific grant from funding agencies in the public, commercial, or notfor-profit sectors.

Ethical approval Not applicable.

Consent to participate Not applicable.

Consent to publish Not applicable.

Availability of data and materials The authors confirm that the data supporting the findings of this study are available within the article.

\section{References}

1. Equbal A, Equbal MI, Badruddin IA, Algahtani A (2021) A critical insight into the use of FDM for production of EDM electrode. Alexandria Engineering Journal

2. Jiang K, Wu X, Lei J, Hu Z, Gao G, Tang Y, Diao D (2021) Investigation on the geometric evolution of microstructures in EDM with a composite laminated electrode. J Clean Prod 298:126765 
3. Singh H, Singh J, Sharma S, Chohan JS (2021) Parametric optimization of MRR \& TWR of the Al6061/SiC MMCs processed during die-sinking EDM using different electrodes. Materials Today: Proceedings

4. Li G, Natsu W, Yu Z (2021) Elucidation of the mechanism of the deteriorating interelectrode environment in micro EDM drilling. International Journal of Machine Tools and Manufacture 103747

5. Li G, Natsu W (2020) Realization of micro EDM drilling with high machining speed and accuracy by using mist deionized water jet. Precis Eng 61:136-146

6. Sathishkumar GB, Arockiam AJ, Alagarsamy SV, Sethuraman P, Chanakyan C, Chairman CA, ... Kumar SD (2021) Influence of EDM parameters on Al203\& Gr reinforced aluminium matrix composites. Materials Today: Proceedings

7. Davim JP, Maranhão C, Cabral G, Grácio J (2009) Performance of cutting tools in machining Cu/W alloys for application in EDM electrodes. International Journal of Refractory Metals Hard Materials 27(4):676-682

8. Abbas NM, Solomon DG, Bahari MF (2007) A review on current research trends in electrical discharge machining (EDM). International Journal of machine tools Manufacture 47(7-8):1214-1228

9. Hilgenberg K, Behler K, Steinhoff K (2014) Localized dispersing of ceramic particles in tool steel surfaces by pulsed laser radiation. Applied surface science 305:575-580

10. Tröber P, Weiss HA, Kopp T, Golle R, Volk W (2017) On the correlation between thermoelectricity and adhesive tool wear during blanking of aluminum sheets. Int J Mach Tools Manuf 118:91-97

11. Cao J, Brinksmeier E, Fu M, Gao RX, Liang B, Merklein M, ... Yanagimoto J (2019) Manufacturing of advanced smart tooling for metal forming. CIRP Ann 68(2):605-628

12. Abraham T, Bräuer G, Flegler F, Groche P, Demmler M (2020) Dry sheet metal forming of aluminum by smooth DLC coatings-a capable approach for an efficient production process with reduced environmental impact. Procedia Manufacturing 43:642-649

13. Rathmann L, Vollertsen F (2020) Determination of a contact length dependent friction function in micro metal forming. J Mater Process Technol 286:116831

14. Tröber P, Welm M, Weiss HA, Demmel P, Golle R, Volk W (2021) Temperature, thermoelectric current and adhesion formation during deep drawing. Wear 203839

15. Lenz B, Hasselbruch H, Großmann H, Mehner A (2020) Application of CNN networks for an automatic determination of critical loads in scratch tests on aC: $\mathrm{H}$ : W coatings. Surface Coatings Technology 393:125764

16. Vellingiri S, Soundararajan R, Mohankumar N, Nithyananthakumar K, Muthuselvam K (2021) Exploration on WEDM process parameters effect on LM13 alloy and LM13/SiC composites using Taguchi method. Materials Today: Proceedings 45, 997-1003

17. Johny A, Thiagarajan C (2020) Investigation of surface integrity and it's optimization on pure titanium using molybdenum wire by reciprocated travelling WEDM-A review. Materials Today: Proceedings 33, 2581-2584

18. Pramanick A, Mandal S, Dey PP, Das PK (2021) Comparative analysis for the prediction of WEDM responses for machining spark plasma sintered boron carbide ceramic sample by RSM and ANFIS. Materials Today: Proceedings 41, 1089-1095

19. Lazoglu I, Poulachon G, Ramirez C, Akmal M, Marcon B, Rossi F, ... Krebs M (2017) Thermal analysis in Ti6Al-4V drilling. CIRP Ann 66(1):105-108 
20. Pirtini M, Lazoglu I (2005) Forces and hole quality in drilling. International journal of machine tools Manufacture 45(11):1271-1281

21. Saikumar S, Shunmugam MS (2012) Investigations into high-speed rough and finish end-milling of hardened EN24 steel for implementation of control strategies. The International Journal of Advanced Manufacturing Technology 63(1-4):391-406

22. Lu X, Jia Z, Wang H, Feng Y, Liang SY (2019) The effect of cutting parameters on micro-hardness and the prediction of Vickers hardness based on a response surface methodology for micro-milling Inconel 718. Measurement 140:56-62

23. Gao C, Liu Z, Xie T, Guo C (2021) Influence of Electrical Discharge Machining on Thermal Barrier Coating in a Two-Step Drilling of Nickel-Based Superalloy. Arabian Journal for Science Engineering 46(3):2009-2020

24. Kuppan P, Rajadurai A, Narayanan S (2008) Influence of EDM process parameters in deep hole drilling of Inconel 718. The International Journal of Advanced Manufacturing Technology 38(1):74-84

25. Kumar K, Rawal SK, Singh VP, Bala A (2018) Experimental study on diametric expansion and taper rate in EDM drilling for high aspect ratio micro holes in high strength materials. Materials Today: Proceedings 5(2), 7363-7372

26. Dilip DG, Panda S, Mathew J (2020) Characterization and parametric optimization of micro-hole surfaces in micro-EDM drilling on Inconel 718 superalloy using genetic Algorithm. Arabian Journal for Science and Engineering 1-18

27. Kumar M, Datta S, Kumar R (2019) Electro-discharge machining performance of Ti-6Al-4V alloy: studies on parametric effect and phenomenon of electrode wear. Arabian Journal for Science Engineering 44(2):15531568

28. Flegler F, Neuhäuser S, Groche P (2020) Influence of sheet metal texture on the adhesive wear and friction behaviour of EN AW-5083 aluminum under dry and starved lubrication. Tribol Int 141:105956

29. Zheng G, Cheng X, Dong Y, Liu H, Yu Y (2020) Surface integrity evaluation of high-strength steel with a TiCN$\mathrm{NbC}$ composite coated tool by dry milling. Measurement 166:108204

30. Correia AE, Davim JP (2011) Surface roughness measurement in turning carbon steel AISI 1045 using wiper inserts. Measurement 44(5):1000-1005

31. Festas AJ, Pereira RB, Ramos A, Davim JP (2021) A study of the effect of conventional drilling and helical milling in surface quality in titanium Ti-6Al-4V and Ti-6AL-7Nb alloys for medical applications. Arabian Journal for Science Engineering 46(3):2361-2369

32. Çetin M, Günen A, Kalkandelen M, Karakaş MS (2021) Microstructural, wear and corrosion characteristics of boronized AISI 904L superaustenitic stainless steel. Vacuum 187:110145

33. Mandaloi G, Singh S, Kumar P, Pal K (2016) Effect on crystalline structure of AISI M2 steel using tungstenthorium electrode through MRR, EWR, and surface finish. Measurement 90:74-84

34. Bahgat MM, Shash AY, Abd-Rabou M, El-Mahallawi IS (2019) Influence of process parameters in electrical discharge machining on H13 die steel. Heliyon 5(6):e01813

35. Kanagarajan D, Karthikeyan R, Palanikumar K, Davim JP (2009) Application of goal programming technique for electro discharge machining (EDM) characteristics of cemented carbide (WC/Co). Int J Mater Prod Technol 35(1-2):216-227 
36. Selvarajan L, Raja R, Sasikumar R, Muralidharan V (2020) Effects of process parameter on performance measures in electrical discharge machining using copper and brass electrodes. Materials Today:

Proceedings

37. Singh NK, Singh Y (2019) Experimental investigation and modeling of surface finish in argon-assisted electrical discharge machining using dimensional analysis. Arabian Journal for Science Engineering 44(6):5839-5850

38. Ahmed A, Boban J, Rahman M (2021) Novel EDM deep hole drilling strategy using tubular electrode with orifice. CIRP Annals

39. Huang SF, Liu Y, Li J, Hu HX, Sun LY (2014) Electrochemical discharge machining micro-hole in stainless steel with tool electrode high-speed rotating. Mater Manuf Processes 29(5):634-637

40. Datta S, Biswal BB, Mahapatra SS (2017) A novel satisfaction function and distance-based approach for machining performance optimization during electro-discharge machining on super alloy Inconel 718.

Arabian Journal for Science Engineering 42(5):1999-2020

41. Ming QY, He LY (1995) Powder-suspension dielectric fluid for EDM. J Mater Process Technol 52(1):44-54

42. Ho KH, Newman ST (2003) State of the art electrical discharge machining (EDM). Int J Mach Tools Manuf 43(13):1287-1300

\section{Tables}

Table 1. Chemical Composition of X153CrMoV12

\begin{tabular}{cclc}
$\begin{array}{c}\text { Carbon } \\
(\mathrm{C})\end{array}$ & $\begin{array}{c}\text { Chrome } \\
(\mathrm{Cr})\end{array}$ & $\begin{array}{c}\text { Molybdenum } \\
(\mathrm{Mo})\end{array}$ & $\begin{array}{c}\text { Vanadium } \\
(\mathrm{V})\end{array}$ \\
\hline 1.55 & 12 & 0.8 & 0.9
\end{tabular}

Table 2. Mechanical and physical properties of X153CrMoV12

$\begin{array}{llll}\text { Usage Hardness (HRC) } & \text { Thermal expansion coefficient } & \text { Heat conductivity }(\mathrm{W} / \mathrm{mK}) & \begin{array}{c}\text { Density } \\ \mathrm{g} / \mathrm{cm}^{3}\end{array} \\ & (\quad & & 7.85\end{array}$

Table 3. EDM micro drill parameters and experimental findings 


\begin{tabular}{llllllllll}
$\begin{array}{l}\text { Exp. } \\
\text { No. }\end{array}$ & $\begin{array}{l}\text { Current } \\
(\mathbf{A})\end{array}$ & $\begin{array}{l}\text { Voltage } \\
(\mathrm{N})\end{array}$ & $\begin{array}{l}\text { Ton } \\
(\boldsymbol{\mu s})\end{array}$ & $\begin{array}{c}\text { Toff } \\
(\boldsymbol{\mu s})\end{array}$ & $\begin{array}{l}\text { Machining } \\
\text { Time } \\
(\mathbf{s e c})\end{array}$ & $\begin{array}{l}\text { Material } \\
\text { Removal } \\
\text { Rate } \\
(\mathrm{mg} / \mathrm{min})\end{array}$ & $\begin{array}{l}\text { Electrode } \\
\text { Wear } \\
\text { Rate } \\
(\%)\end{array}$ & $\begin{array}{l}\text { Ra Surface } \\
\text { Roughness } \\
(\boldsymbol{\mu} \mathbf{s})\end{array}$ & $\begin{array}{l}\text { White } \\
\text { Layer } \\
\text { Hardness } \\
\left(\mathrm{HV}_{0.10}\right)\end{array}$ \\
\hline 1 & 7 & 2 & 26 & 3 & 42 & 372.857 & 3.518 & 4.97 & 589 \\
\hline 2 & 7 & 3 & 26 & 3 & 35 & 481.714 & 3.787 & 8.31 & 597 \\
\hline 3 & 7 & 1 & 26 & 3 & 66 & 179.090 & 2.655 & 5.11 & 596 \\
\hline 4 & 6 & 2 & 26 & 3 & 48 & 298.750 & 3.221 & 6.14 & 597 \\
\hline 5 & 6 & 3 & 26 & 3 & 36 & 435.000 & 3.518 & 6.95 & 596 \\
\hline 6 & 6 & 1 & 26 & 3 & 68 & 194.117 & 2.965 & 4.71 & 596 \\
\hline 7 & 5 & 2 & 26 & 3 & 56 & 240.000 & 3.019 & 4.44 & 598 \\
\hline 8 & 5 & 3 & 26 & 3 & 41 & 349.756 & 3.221 & 4.88 & 599 \\
\hline 9 & 5 & 1 & 26 & 3 & 88 & 147.954 & 2.924 & 5.83 & 597 \\
\hline 10 & 7 & 3 & 23 & 3 & 33 & 509.090 & 3.774 & 8.31 & 597 \\
\hline 11 & 7 & 3 & 29 & 3 & 29 & 583.448 & 3.801 & 6.28 & 580 \\
\hline 12 & 7 & 3 & 29 & 4 & 32 & 480.000 & 3.450 & 5.81 & 626
\end{tabular}

Figures 


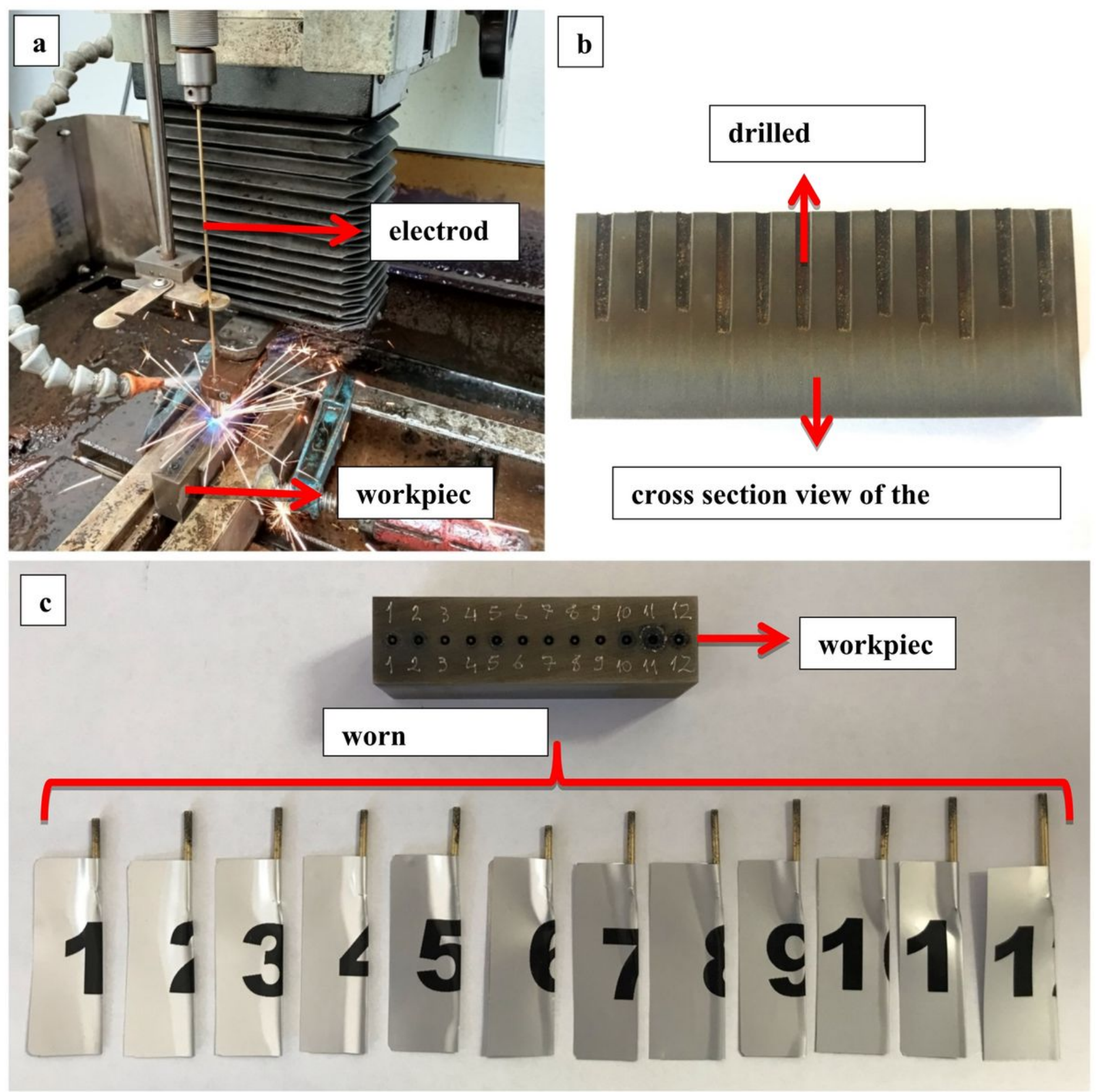

Figure 1

Machining centers (a) EDM (OSCARMAX SD400 ZNC), (b) cutaway view, (c) experiment materials 
a

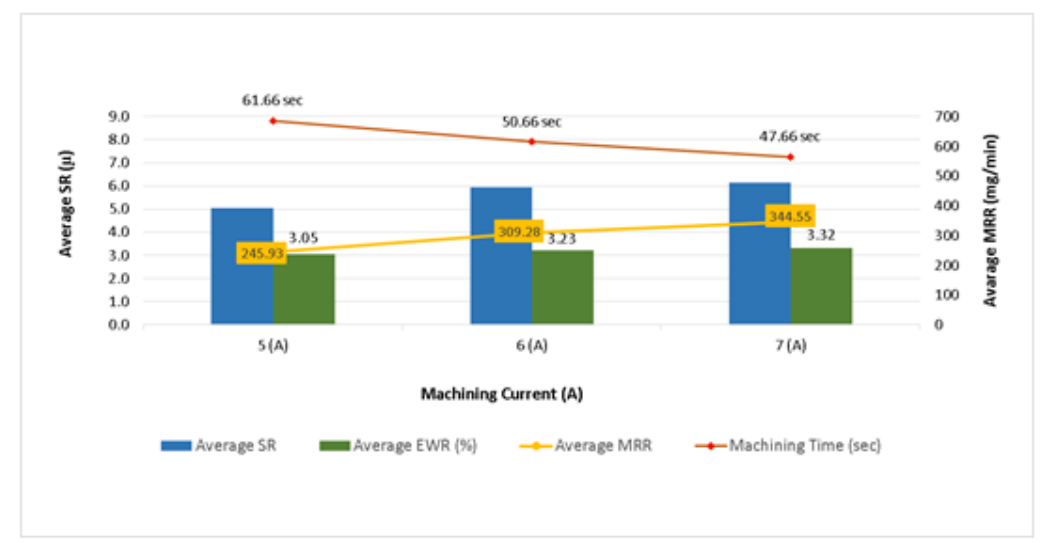

b

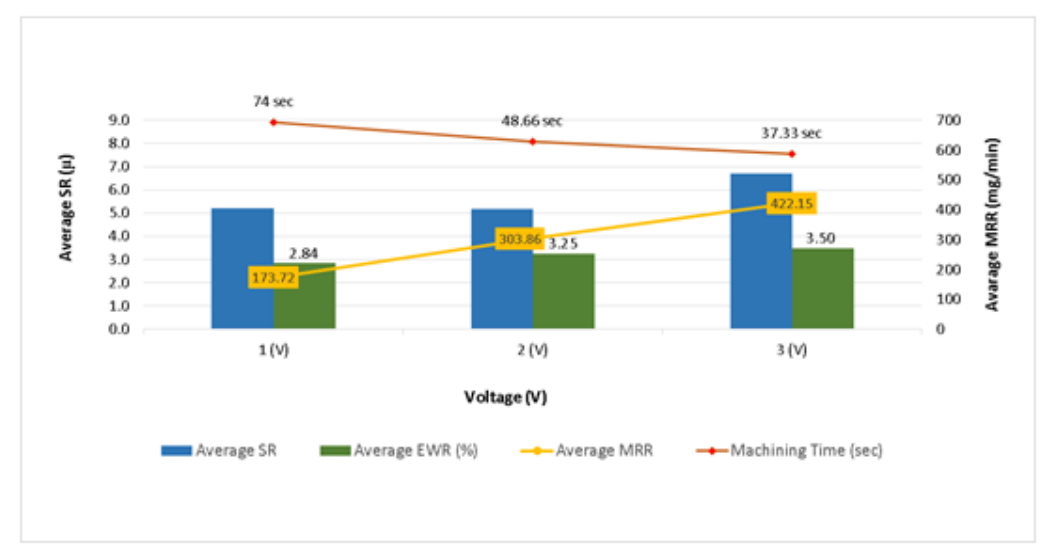

c

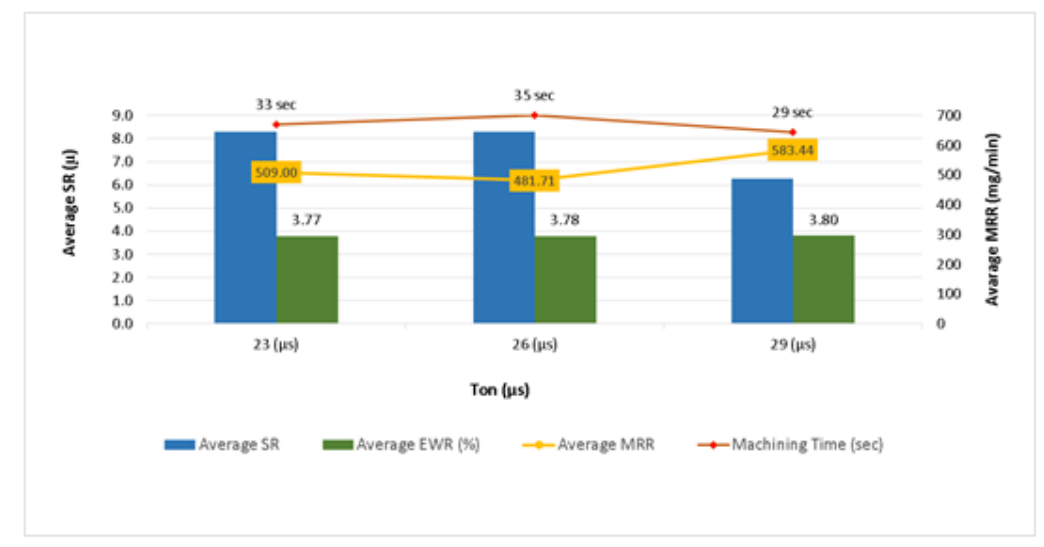

Figure 2

Effects of machining parameters on drilling quality: a According to the increasing current. b According to the increasing voltage $c$ According to the changing Ton 


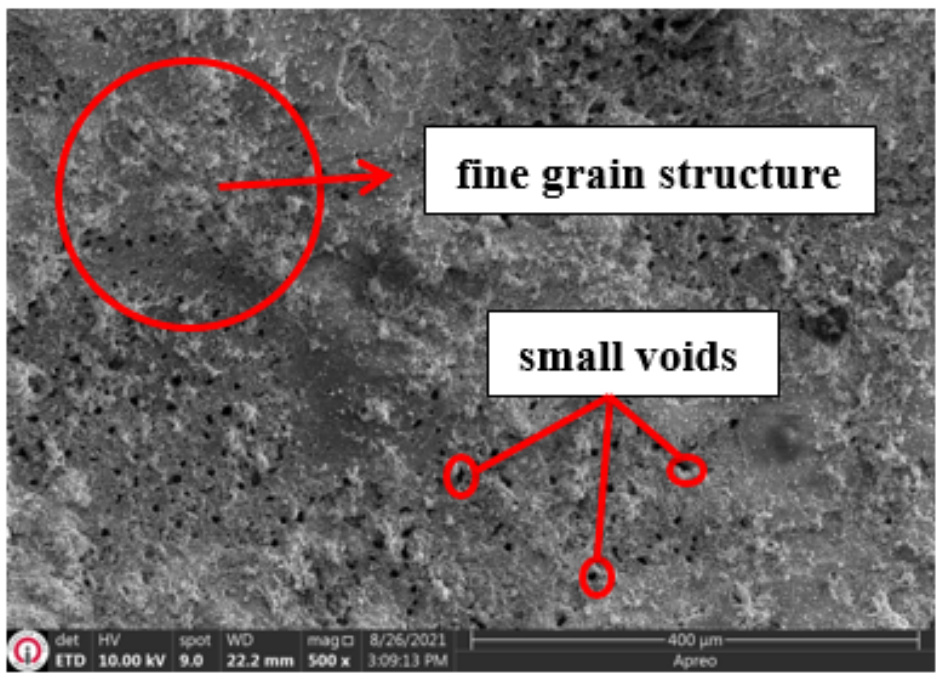

(a)

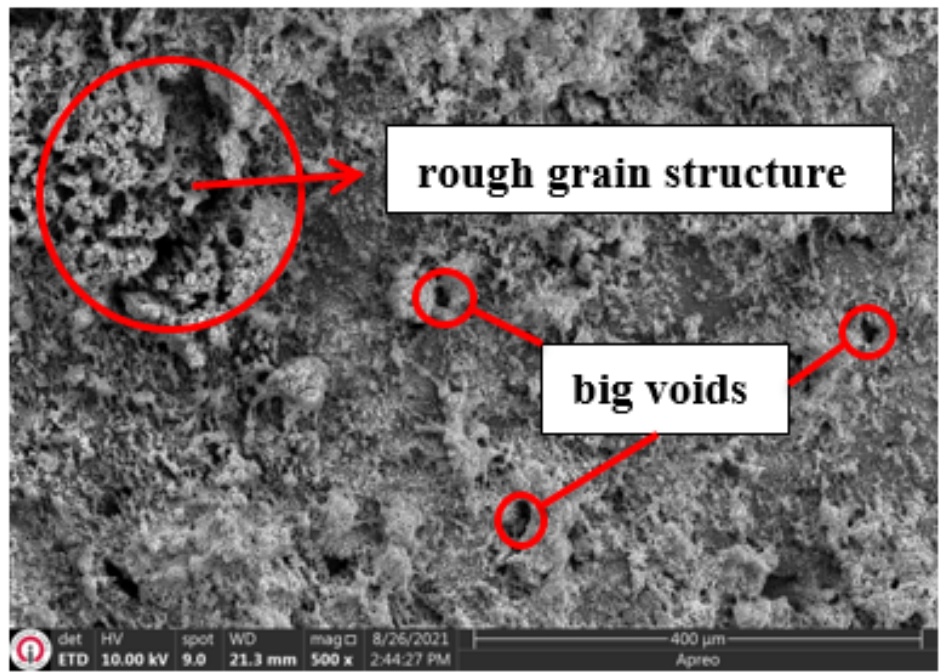

(b)

Figure 3

SEM Micrographs of machined surface a the smoothest surface (Experiment no. 7), $b$ the roughest surface (Experiment no. 10)

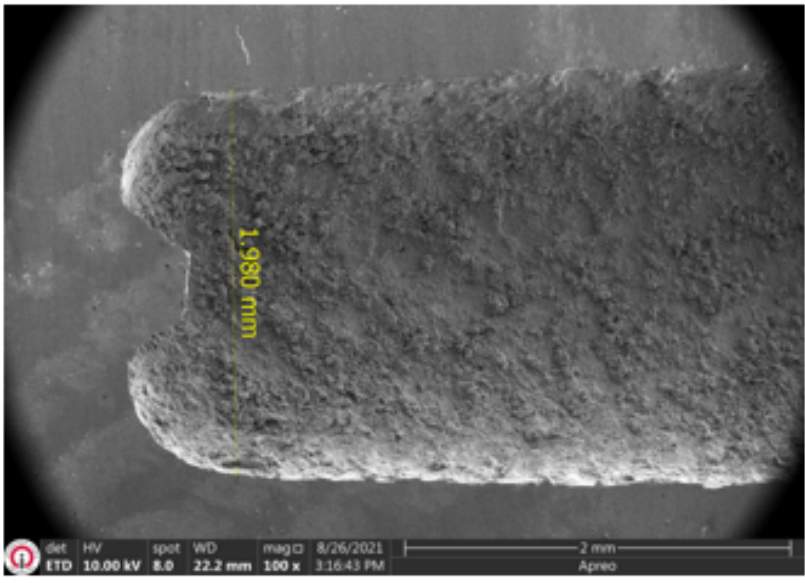

(a)

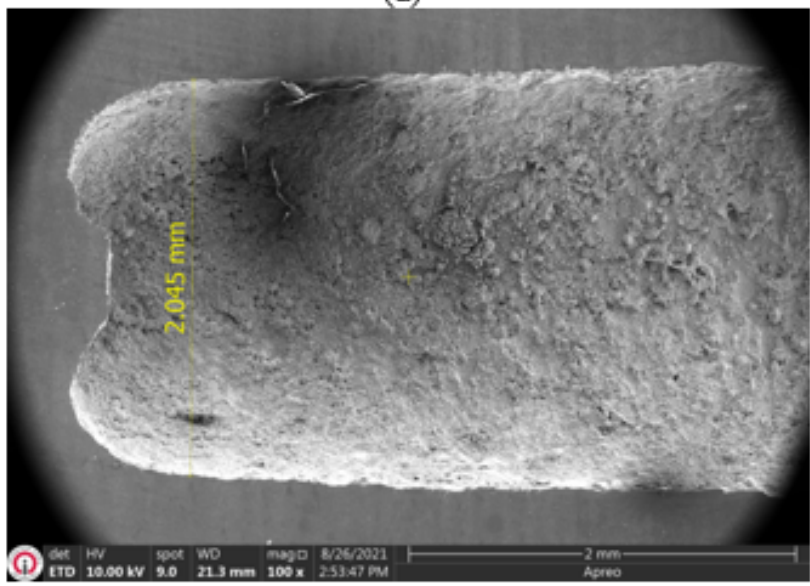

(c)

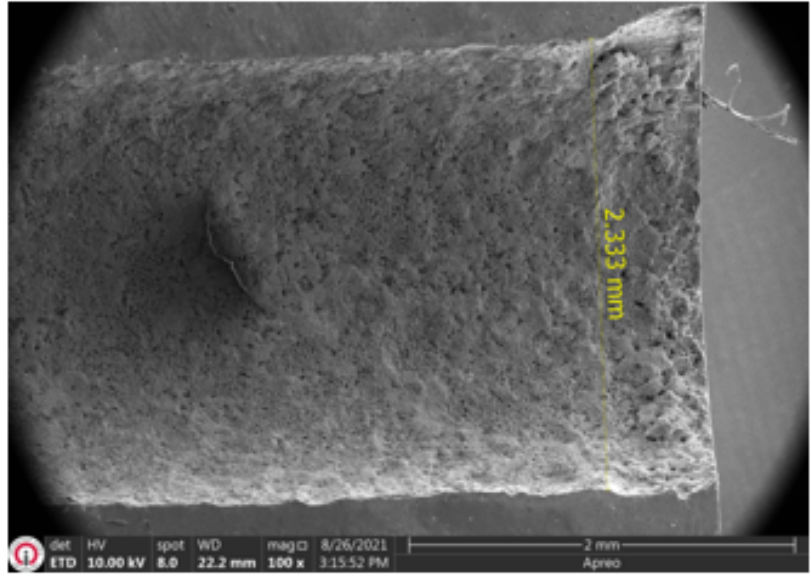

(b)

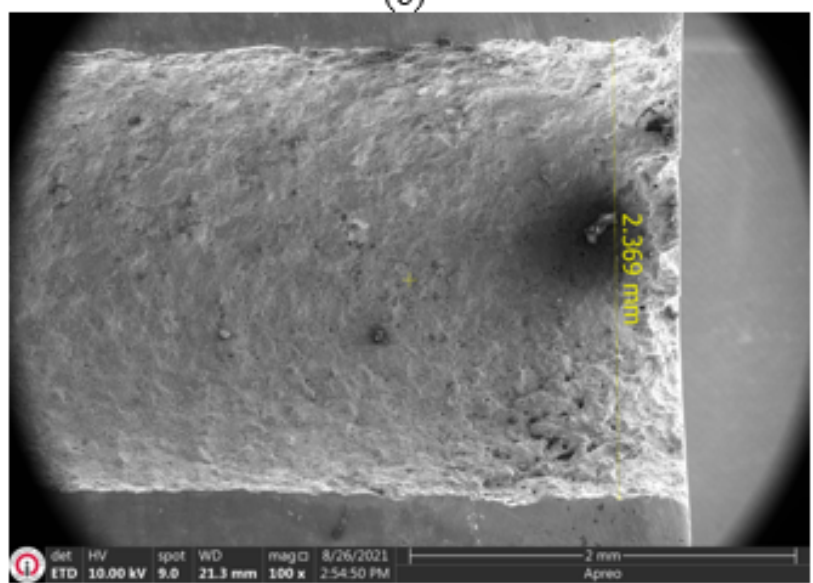

(d)

Figure 4 
SEM Micrographs of electrode wear effects: a Experiment no. 4 head, b Experiment no. 4 inlet, c Experiment no. 10 head, d Experiment no. 10 inlet

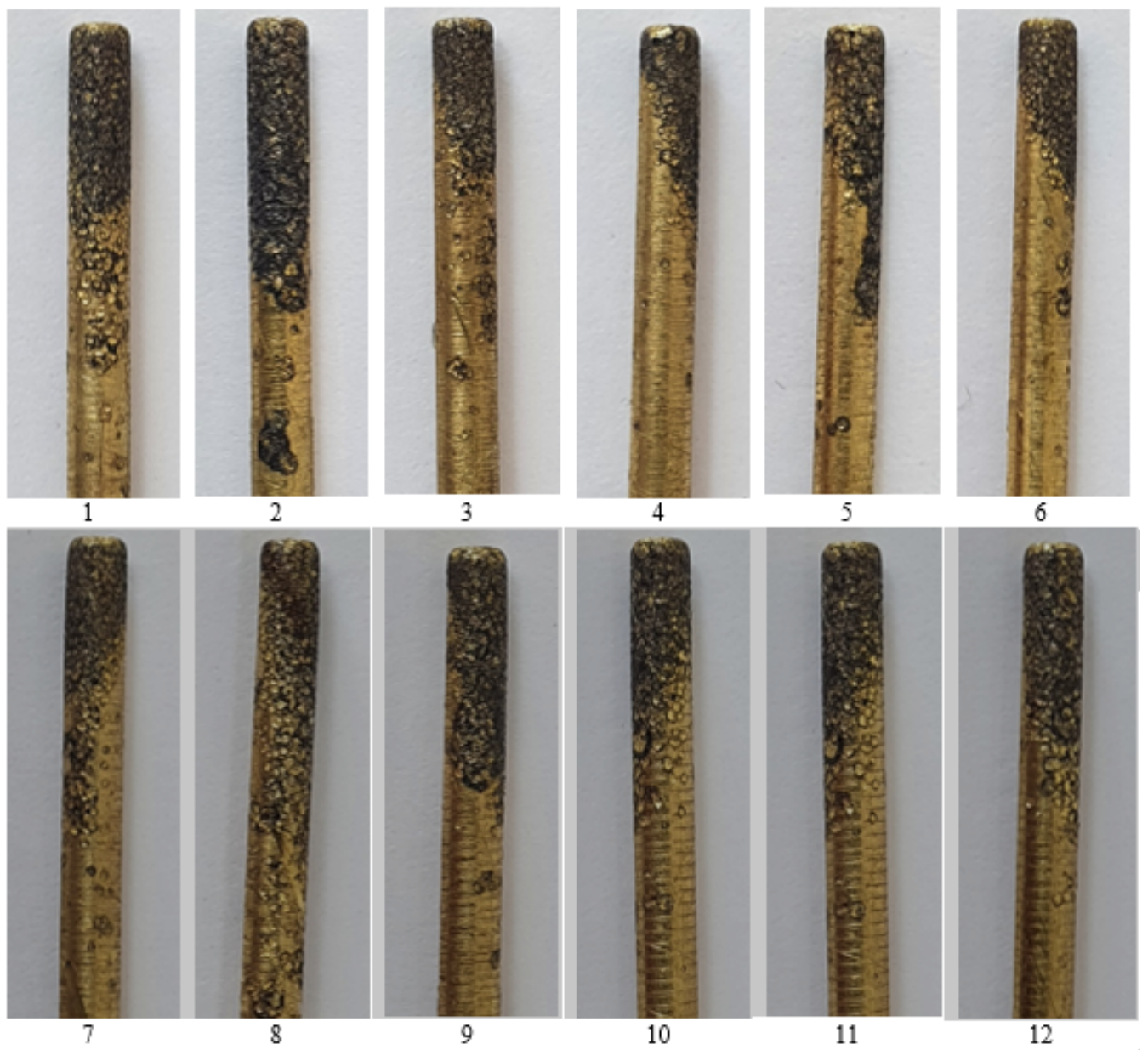

Figure 5

Worn electrode tips used in the experiment 

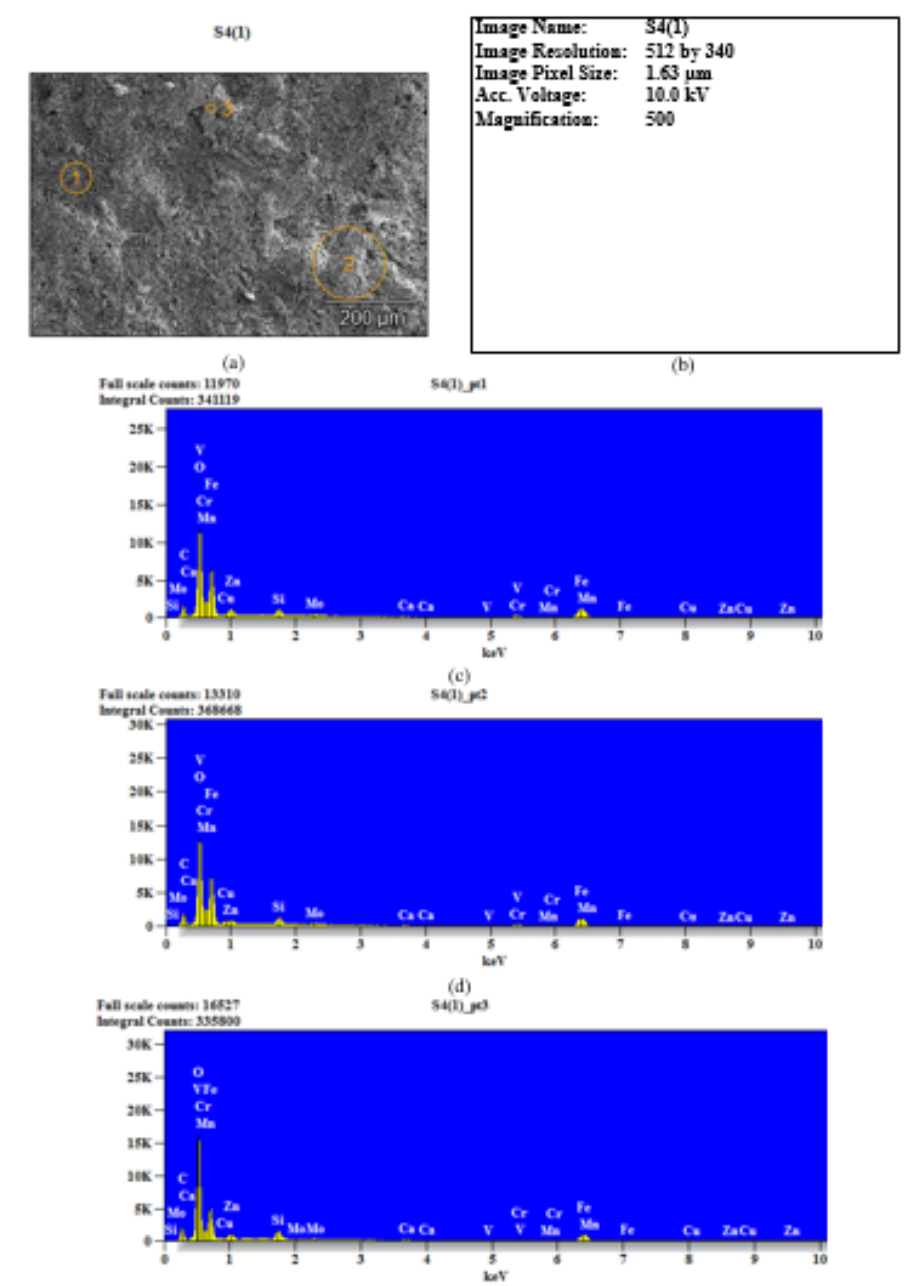

(c)

\section{Figure 6}

EDS analysis of Brass electrode residues found on machined surfaces (Experiment no. 4)

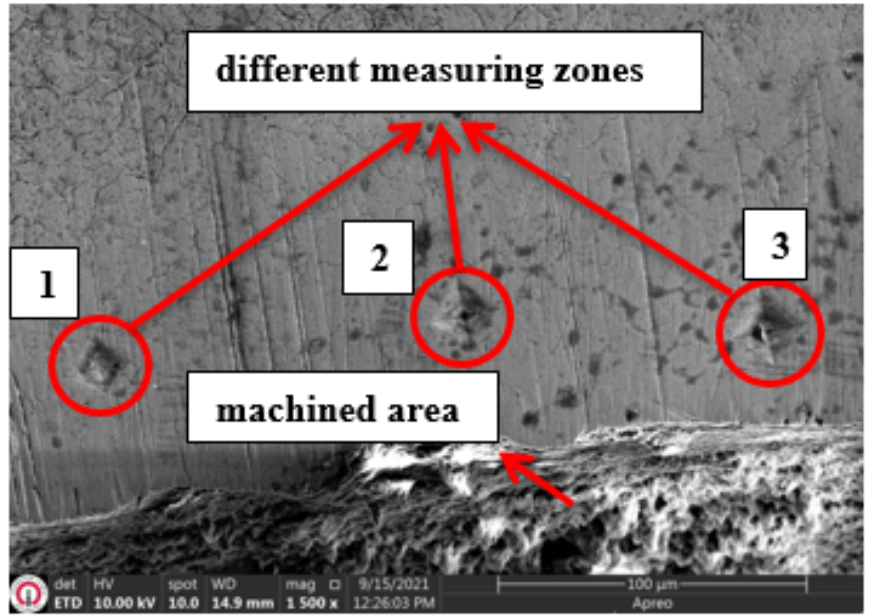

(a)

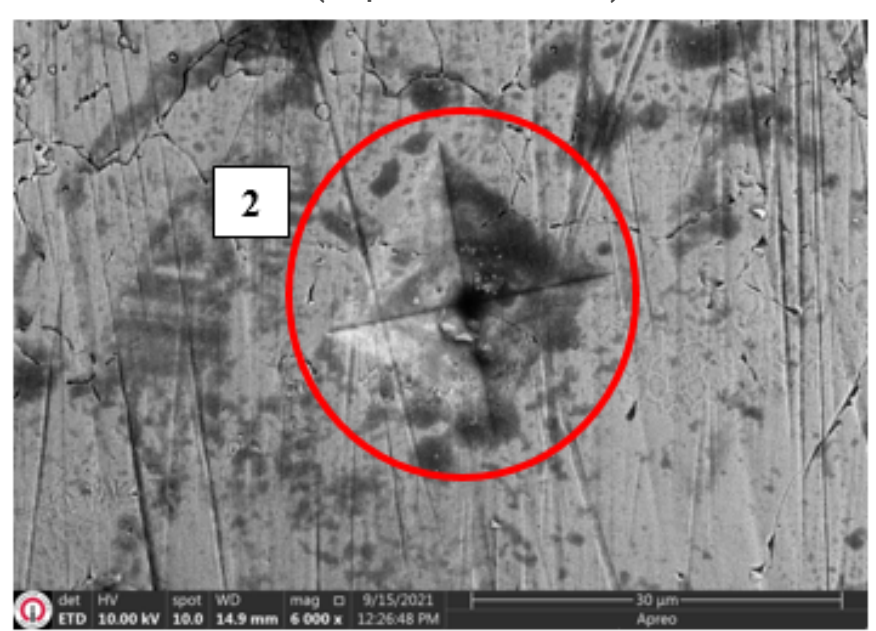

(b)

\section{Figure 7}

Hardness measurement near region of white layer (Experiment no. 5): a Measuring zone, b Measuring point. 


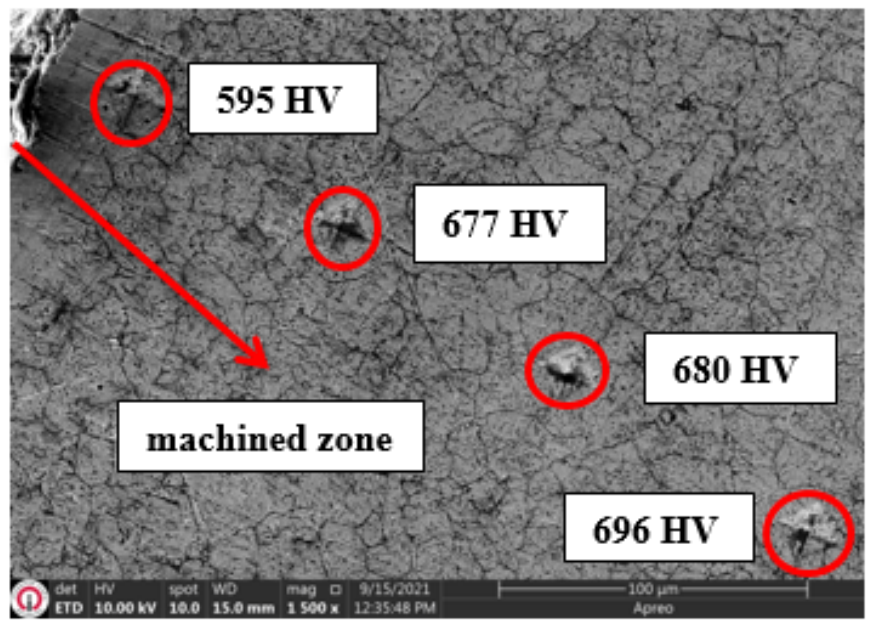

(a)

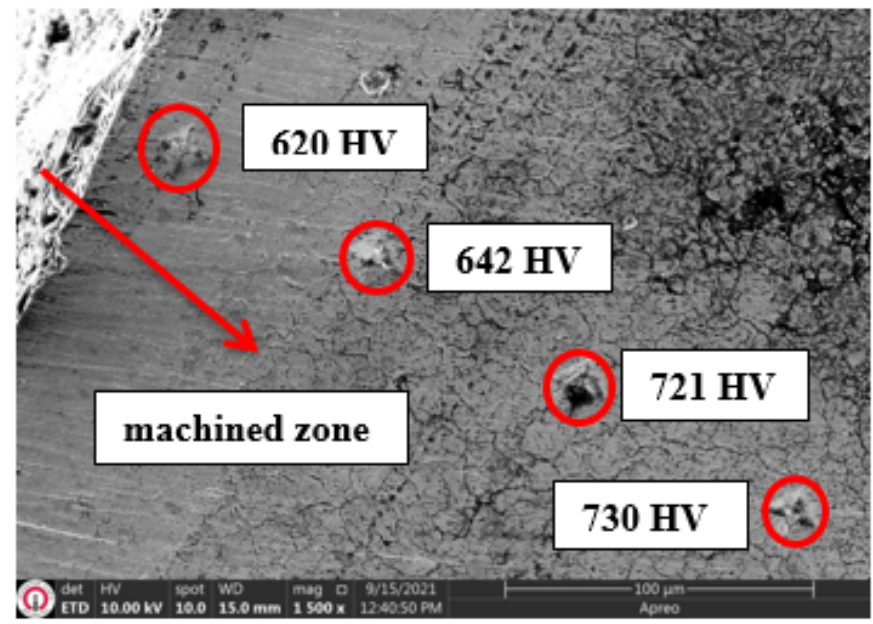

(b)

\section{Figure 8}

Hardness measurement points and values: a Machining time $56 \mathrm{sec}$ (Experiment no. 7), b Machining time 33 sec (Experiment no. 10)

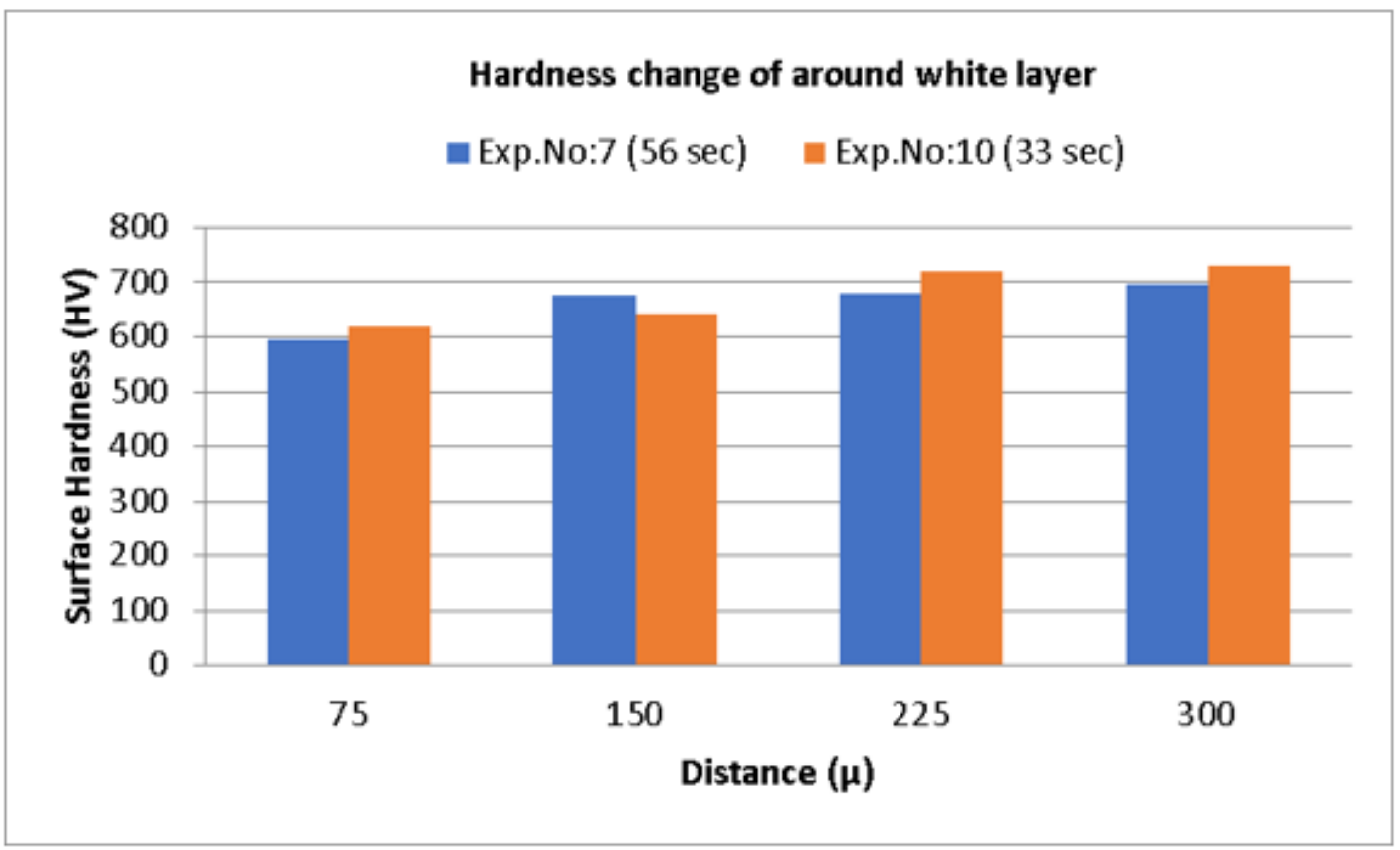

\section{Figure 9}

Hardness change according to the distance from the machining area 